\title{
Effect of Learning Style and Intelligence type on Academic Performance of Nursing Students
}

\author{
Alia Amin \\ Lahore School of Nursing, The University of Lahore, Lahore, Pakistan
}

\begin{abstract}
Learning styles are unique for every student and therefore varies from student to student. According to VARK model there are four modules of learning characteristics which are Visual, Aural, Read/Write and Kinesthetic. Different students have different learning preferences and they can be categorized accordingly.

Intelligence can be defined as a person's intellectual potential. This potential is different for every individual. It is always be of controversy to judge intellectual potential, however different theories proposed with time to conceptualize intelligence.
\end{abstract}

Keywords: VARK (Visual, Auditory, Read/Write, Kinesthetic), Multiple Intelligence, Academic performance.

DOI: $10.7176 / \mathrm{JHMN} / 62-20$

Publication date:May $31^{\text {st }} 2019$

\section{Introduction}

A learning style can be described as a person's own way to responding a stimulus in order to learn something. Learning styles are composite of three major characteristics affective, cognitive and the physiological factor. These are indicators are determinants of how a person respond to the learning stimuli in a learning condition. In more simple terms learning style is the unique educational environment in which a learner has more chances to learn. It has been founded that in higher education students came from diverse ethnic and cultural backgrounds and have different learning capabilities (Samarakoon, Fernando, Rodrigo, \& Rajapakse, 2013).

In 1988, Neil Fleming worked to know the learning style of each student and ended up in building a questionnaire that can be used to acquire information about learning style, named as "VARK", this tool has proved its efficacy in knowing the learning style of students. Fleming modified the previously known "VAK" into "VARK" by dividing the visual ability into two modules, $V=$ True visual and $R=$ Read/Write (AlKhasawneh, 2013).

True visual learners (V), learn best when they got information in form of some clear images, graphics, videos or vigorous figures. They are more directed toward printed stuff which include flow sheets, charts, hierarchies or designed models. Aural learners (A) get more attracted towards audio learning, aural learners are good listeners and they tend to learn by focusing on each word delivered by lecturers. Aural learners are less interested in taking down notes instead, they prefer to hear the recorded lectures in order to maximize their learning. Aural learners mostly founded to read loudly quite enough to hear their own voice pronouncing. Read/Write learners (R) have their own unique mode of learning, these learners learn by both reading and writing, Read/Write learners are keen note-makers in the lecture these are intended to note down every single detail of given lecture. Read/Write learners best learn by getting stimuli through notes, books and handouts. Kinesthetic learners $(\mathrm{K})$ are more unique in their nature, kinesthetic learners learn from experiencing something. These type of learners learn only when they get involved in a situation where they can make touch and feel the physical appearance of an object, in simple, kinesthetic learners are experimental learners (Prithishkumar \& Michael, 2014).

Learning styles are unique for every student and therefore varies from student to student. According to VARK model there are four modules of learning characteristics which are Visual, Aural, Read/Write and Kinesthetic. Different students have different learning preferences and they can be categorized accordingly. Learners who only has one dominant learning style present in them are said to be "unimodal", students having two learning modules present are classified as "bimodal", "tri-modal" terminology is used to describe the learners who have three modules of learning and "multi-modal" learners are those who have more than two learning capabilities present in them. For the maximum learning outcome it is mandatory to know and provide the most suitable learning environment to a student (Laxman, Sandip, \& Sarun, 2014).

Intelligence can be defined as a person's intellectual potential. This potential is different for every individual. It is always be of controversy to judge intellectual potential, however different theories proposed with time to conceptualize intelligence. One most fascinating theory is proposed by Harvard psychologist, Howard Gardner. In 
Dr. Gardner proposed theory multiple intelligence is accounted for bringing intelligence in humans from childhood to older adults. This multiple intelligence theory also has its strong implicit on learning process of adults(Lunenburg \& Lunenburg, 2014).

In Gardner multiple intelligence theory, seven type of intelligence is proposed; Mathematical/logical - the intellectual ability of an individual to get things logically and to solve mathematical problems; Linguistic/verbal the persons' ability to get something that is written or spoken and enables him to do better communication; Spatial - the intelligence which enables a person to get benefit from close spaces as well as from open spaces; Bodykinesthetic - this includes physical co-ordination along with the use of body or body parts to solve a problem; Musical/rhythmic - ability of a person to enjoy and create music sensation, this type of intelligence enables a musician to make new musical instruments, tunes, pitches and rhythms. Interpersonal - intellectual ability that makes a person good in developing relationship with other persons and enhances interpersonal relationships ; Intrapersonal - intelligence that brings self-actualization, this type of intelligence helps to understand own-self, fears, preferences and addresses own strengths and weaknesses (Macnamara, 2016).

Research and observational studies show that there is no person with universal set of intelligence. Every person has its own intellectual ability which ultimately differs from other person's intellectual ability. These intelligence types have their strong impact over learning process because learning is bounded to intellectual potential. Learning style and intelligence type are the two factors which broadly effect the learning within an academic environment' by knowing the learning style and intelligence type of nursing students their academic performance can be improved (Vizeshfar \& Torabizadeh, 2018).

1.2. Aim of the Study: The Aim of the study is to know the effect of learning style and intelligence type, on academic performance of nursing students.

1.3. Significance of the Study: For participants: after the completion of research study the participant also got the whole picture about effects of learning style and intelligence type on their academic performance. This thing will help them to improve their learning capabilities by improving their understanding about their own learning style and intelligence type.

For institute: upon completion of the research study the generalized results will be discussed with the authoritative persons of corresponding institute, this thing will help them to improve their students' performance by knowing the effects of learning styles and intelligence type on their students' academic performance.

For researcher: the research study will serve as a paradigm for researcher's own understanding about the effect of learning style and intelligence type on nursing student academic performance. Hence researcher can improve her own academic performance.

\section{Litreture Review:}

Learning styles are the general indicators that describe simply that what the process of learning for an individual is. Learning styles are also very useful in knowing the potential of an individual to learn things and his/her level to get excellence in a learned objective or program. To develop a better understanding and maximize the learning process of nursing students knowing their learning style is essential. Research study has shown that students tend to have more than one type of learning style present in them. Learning styles have a very strong impact over academic performance of nursing students as learning only possible when stimuli provided is according to learning style (Wilkinson, Boohan, \& Stevenson, 2014).

However, according to a research study conducted in Pakistan to determine the frequency of learning styles in students, shows that the learning styles and related learning environment is not directly related with students' academic performance. No significant relationship between learning style and learning method was observed $(\mathrm{p}=0.171)$. The same study also reveals that there is no strong relation $(\mathrm{p}=0.318)$ present between learning style and academic performance (Bhalli, Khan, \& Sattar, 2016).

Adding to, the research conducted to study the learning styles of nursing students shows that, about $55 \%$ of nursing students have multimodal tendency, $45 \%$ of students reported one dominant partiality. Study results also describes that kinesthetic learning style is present in about $60 \%$ of multimodal students whereas, auditory preference is for only $40 \%$ of students (AlKhasawneh, 2013).

On the other hand, a research study shows that most of nursing students (14.8\%) develops a "Diverging" learning 
style. The researcher doesn't find significant correlation in self-directed learning and learning styles. The study participants had slight curiosity about self-directed learning and its relationship with learning style. No analytical significant variation was observed in learning style and reediness of self-directed learning $(\mathrm{P}=0.47)$. Most of the students $(40.8 \%)$ shows positive respond towards learning according to their own learning style (AbuAssi \& Alkorashy, 2016).

Moreover, a research study conducted also establishes the theory of presence of more than one type of learning styles in students, however this study results shows that only one learning style can be dominant in a student. According to the research, a total of 140 students were taken as sample from them, 98 individuals (70\%) preferred only one type of the learning styles, while as, 42 (37\%) individuals preferred combinative learning module. Reading-writing learners were 43 students but the most frequent style among multimodal learners was auditory style which was selected only by $45 \%$ of the participants (Moghadam, Moghadam, Rostaminejad, \& Salehian, 2015).

Furthermore, a research was study conducted in the learning environment to find the association between intellectual ability and grade point average of nursing students. This study result revealed that, intellectual ability predicts academic performance, but the mechanism for this correlation is unclear. There is also evidence that emotional intelligence contributes to students' cognitive performance. The results of the study shows the positive significant relationship of emotional intelligence with average grades $(r=.25)$ and $\mathrm{p}$ value $(>.05)$ (Codier \& Odell, 2014).

In a likewise study which was conducted to know the relationship between academic performance and intelligence type, calculation for mean assignment scores was performed. This research study shows that the intelligence type is directly related with academic performance especially in higher education. Researcher reveals that if a student chooses and adopts a learning environment according to intellectual ability then he can perform better. Academic performance is highly correlated with intelligence scores $(\mathrm{r}=0.16, \mathrm{~N}=138, \mathrm{P}<0.05)$, (Rankin, 2013).

Consequently, another study aimed to know the effect of intelligence type on students' academic performance also suggests that the intelligence style is unique for every individual. Therefore best academic results can only be achieved by understanding the intelligence type and adopting relevant education style (Ahvan, 2015)

Moreover, a study conducted in Iran also suggests that there is positive correlation between multiple intelligence and academic performance. The researcher also found that the multiple intelligences are interconnected. Here too results of the study confirmed the claim of Gardner. He says that although multiple intelligences are separate units but they support each other whenever a task is performed (Ahvan \& Pour, 2016).

A likewise study conducted in India shows that different students possessed different forms of intelligences and most students had more than one forms of intelligence. Of seven forms of intelligence, only three forms of intelligence such as logical/mathematical, musical, and spatial were positively correlated with the IQ score (Singh et al., 2017)'.

3. Methodology:

3.1. Study Design: A correlational descriptive study design was used in this study.

3.2. Setting: Setting for conducting the research was Lahore School of Nursing, The University of Lahore.

3.3. Study Population: Target population for conducting the research were nursing students from 2 Year Post RN (BSN) and 4 Year Generic BSN of University of Lahore.

3.4. Sample Size: Sample size calculated by using the Solvin's formula.

$\mathrm{n}=\mathrm{N} / 1+\mathrm{N}(\mathrm{e}) 2$

3.5. Sampling Technique: Convenient, non-probability randomized sampling technique was used in sample selection.

3.6. Data Analysis: Collected analyzed by using Statistical Package for Social Sciences (SPSS) version 21.

\subsection{Ethical Consideration:}

$>$ Ethical clearance letter from institutional review board committee of University of Lahore must be taken before carrying out research work.

$>$ The study will be conducted in Lahore School of Nursing after getting approval from HOD/Dean.

$>$ The rules and regulations of respective department will not be violated. 
Each member who will participant in this study will be provided with an informed consent form and only those questionnaire will be considered who have signed consent form.

$>$ All information about respondents will be kept confidential.

$>$ Self-respect of all the participants will kept intact and each participant will be given the right to withdraw himself from the research process any time he wants.

\section{Results}

No person will be forced to take part in the study.

\section{1: Demographic data analysis \& results:}

This chapter consists of three sections. Section 1 represents the demographic characteristics of the participants whereas section 2 consist of frequency and percentage of dependent and independent variables. And section 3 consist of correlation of Learning Style and Intelligence type with academic performance. (dependent and independent variables).

\section{Table1:}

\begin{tabular}{|c|c|c|c|}
\hline \multirow[t]{2}{*}{ Characteristics } & \multirow[t]{2}{*}{ Category } & \multicolumn{2}{|c|}{ Respondents } \\
\hline & & Number & Percentage \\
\hline \multirow[t]{2}{*}{ Gender } & Male & 24 & 21.8 \\
\hline & Female & 86 & 78.2 \\
\hline \multirow[t]{2}{*}{ Age Group } & $15-25 \mathrm{y}$ & 24 & 21.8 \\
\hline & $26-30 y$. & 62 & 56.4 \\
\hline \multirow{8}{*}{$\begin{array}{l}\text { Academic } \\
\text { (Semester) }\end{array}$} & $31-36 y$. & 24 & 21.8 \\
\hline & 1st Semester & 0 & 0.0 \\
\hline & 2nd Semester & 31 & 28.2 \\
\hline & $3^{\text {rd }}$ Semester & 14 & 12.7 \\
\hline & 4th Semester & 31 & 28.2 \\
\hline & 5th Semester & 16 & 14.5 \\
\hline & $6^{\text {th }}$ Semester & 18 & 16.4 \\
\hline & $7^{\text {th }}$ Semester & 0 & 0.0 \\
\hline \multirow{7}{*}{$\begin{array}{l}\text { Previous Examination } \\
\text { Scores in Percentage }\end{array}$} & $90-100$ & 0 & 0.0 \\
\hline & $80-89$ & 24 & 21.8 \\
\hline & $70-79$ & 12 & 10.9 \\
\hline & $60-69$ & 20 & 18.2 \\
\hline & $55-59$ & 24 & 21.8 \\
\hline & $50-54$ & 30 & 27.3 \\
\hline & $0-49$ & 0 & 0.0 \\
\hline \multirow[t]{3}{*}{ Academic Programme } & $\begin{array}{l}\text { Diploma in } \\
\text { Nursing }\end{array}$ & 0 & 0.0 \\
\hline & $\begin{array}{l}\text { BS Nursing } \\
\text { (Generic) }\end{array}$ & 56 & 50.9 \\
\hline & $\begin{array}{l}\text { BS Nursing (Post } \\
\text { RN) }\end{array}$ & 54 & 49.1 \\
\hline
\end{tabular}

Description: The participants included in the study were $21.8 \%$ (24) male and $78.2 \%$ (84) were female. According to age group $21.8 \%(24)$ was between age of $15-25(62), 56.4 \%$ between the age of $26-30$, however $21.8 \%$ (24) were between $31-36$. The academic year related to response of the participants showing that $28.2 \%(31)$ participants were from $2^{\text {nd }}$ semester, $12.7 \%(14)$ were from $3^{\text {rd }}$ semester,28.2\% (31)were from $4^{\text {th }}$ semester, $14.5 \%(16)$ from $5^{\text {th }}$ semester and $16.4 \%(18)$ were from $6^{\text {th }}$ semester. Moreover, previous examination score percentage of the respondents were showing that $21.8 \%$ (24) of the participants were got score about $80-89 \%, 10.9 \%$ (12) participants were got $70-79 \%$ marks in previous examination. While , $18.2 \%$ (20) of the participants were got $60-69 \%$ score, $21.8 \%$ (24) of the participants were got $55-59 \%$ and $27.3 \%$ (30) of the participants were got $50-54 \%$ score in the previous examination. The education status of the respondents shows that $50.9 \%$ (56) participants were from BS Nursing 4-year generic program and 49.1\% (54) from 2-year BSN (post RN) program.

Table 2: Mean and standard deviation of Learning styles and multiple intelligence.

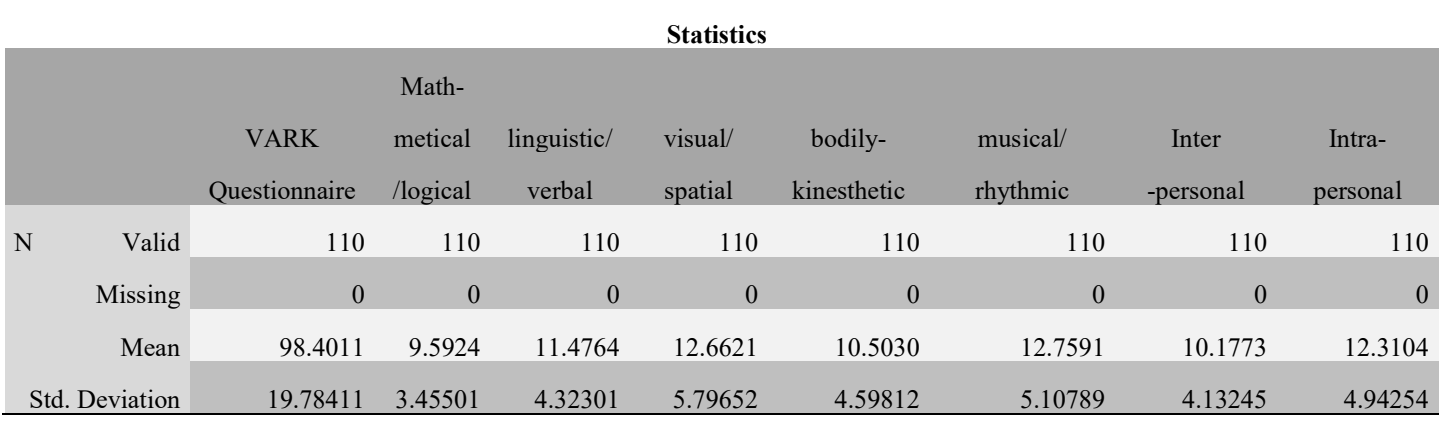




\section{Normality:}

The normality assumption was measured and analyzed by measures of skewness and kurtosis as reported in Table 4 and 5 . Visual confirmation was provided in histogram of a frequency distribution.

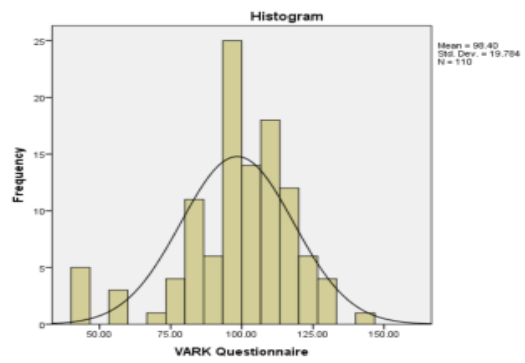

Table 3: Normality of VARK Scale

Figure 3: Normality of VARK Scale

\begin{tabular}{lr}
\hline \multicolumn{2}{|c}{ Statistics } \\
\hline \multicolumn{2}{|c}{ VARK Questionnaire } \\
\hline N Valid & 110 \\
Missing & 0 \\
\hline Skewness & -.973 \\
\hline Std. Error of Skewness & .230 \\
\hline Kurtosis & 1.441 \\
\hline Std. Error of Kurtosis & .457 \\
\hline
\end{tabular}

Table 4: Normality of Multiple Intelligence Scale

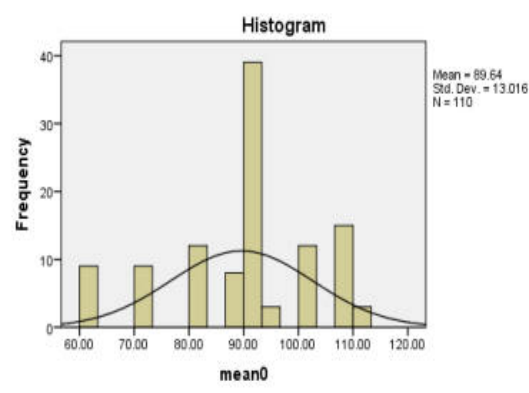

\begin{tabular}{|c|c|c|}
\hline \multicolumn{3}{|c|}{ Statistics } \\
\hline \multicolumn{3}{|c|}{ Multiple Intelligence } \\
\hline $\mathrm{N}$ & Valid & 110 \\
\hline & Missing & 0 \\
\hline & & -.592 \\
\hline & kewness & .230 \\
\hline & & -.130 \\
\hline
\end{tabular}

Figure 4: Normality of Multiple Intelligence Scale

Std. Error of Kurtosis

.457

Description: The frequency distributions were plotted in a histogram illustration with an overlaying normal curve shown in Figure 4 and 5. The overlaying curve represents a typical normal bell curve shape and form for the dependent variable distribution. Distribution normality was also found in the coefficient for skewness and kurtosis. Skewness and kurtosis determine "goodness of fit" of data to a specific distribution such as the normal distribution.

Table 5: Correlation of Learning style with Academic performance.

\begin{tabular}{|c|c|c|c|}
\hline \multicolumn{4}{|c|}{ Correlations } \\
\hline & & VARK Scale & Academic Performance \\
\hline VARK & Pearson Correlation & 1 & $-.305^{* *}$ \\
\hline \multirow[t]{2}{*}{ Scale } & Sig. (2-tailed) & & .001 \\
\hline & $\mathrm{N}$ & 110 & 110 \\
\hline Academic & Pearson Correlation & $-.305^{* *}$ & 1 \\
\hline Performan & Sig. (2-tailed) & .001 & \\
\hline ce & $\mathrm{N}$ & 110 & 110 \\
\hline
\end{tabular}

Description: There was no association between learning styles and academic performance. The results show the negative correlation between learning styles and academic performance. The correlation and level of significance between learning styles and academic performance was-. 305 and .001 consistently. 
Table 10: Correlation of Multiple Intelligence with Academic performance.

\begin{tabular}{lllll}
\hline & & Correlations & & \\
& & & \\
& & Academic Performance \\
Multiple & Pearson Correlation & Multiple Intelligence & 1 & $.369^{* *}$ \\
Intelligence & Sig. (2-tailed) & $\mathrm{N}$ & 110 & .000 \\
& Pearson Correlation & $.369^{* *}$ & 110 \\
Academic & Sig. (2-tailed) & .000 & 1 \\
Performance & $\mathrm{N}$ & 110 & 110
\end{tabular}

**. Correlation is significant at the 0.01 level (2-tailed).

Description: There was an association between Multiple Intelligence and academic performance. The results show the Positive correlation between Multiple Intelligence and academic performance. The correlation and level of significance between intelligence types and academic performance were.369and. 000 correspondingly.

\section{Discussion}

The educational world acknowledging the importance of understanding the students' different learning style preferences and their role in attaining academic success. In the study, therefore, we used VARK learning styles questionnaire to evaluate the learning styles among the students of Lahore school of nursing. To see whether learning styles have any effect on academic achievement, the study also compared different learning styles using Pearson correlation test with academic grades in percentage achieved by students. It was observed that there was no correlation between different learning styles and academic grade. The correlation and level of significance between learning styles and academic performance was- .305 and .001 respectively.

On the other hand, Multiple Intelligence also compared with academic performance, of students. Multiple Intelligence Questionnaire used to see the type of intelligence of students. The results show that the positive correlation was found between Intelligence type and academic performance. While the correlation and level of significance between two values for intelligence types and academic performance were.369 and .000 respectively.

\section{Conclusion}

The study comprises 110 nursing students and shows that different students possessed different learning styles and different forms of intelligences. Current study concluded that learning style have no effect on academic performance of students. While intelligence type effects the academic performance of students. Negative correlation found between learning styles and academic performance. While, Positive correlation found between intelligence type and academic performance.

\section{REFERENCES:}

AbuAssi, N. E., \& Alkorashy, H. A. E. (2016). Relationship between learning style and readiness for self-directed learning among nursing students at king Saud university, Saudi Arabia. International Journal of Advanced Nursing Studies, 5(2), 109-116.

Ahvan, Y. R. (2015). Gardner's multiple intelligences as a predictor of academic performance achievement of high school students. Academic Journal of Psychological Studies, 4(4).

Ahvan, Y. R., \& Pour, H. Z. (2016). The Correlation of Multiple Intelligences for the Achievements of Secondary Students. Educational Research and Reviews, 11(4), 141-145.

AlKhasawneh, E. (2013). Using VARK to assess changes in learning preferences of nursing students at a public university in Jordan: Implications for teaching. Nurse education today, 33(12), 1546-1549.

Ansari, M., Nikneshan, S., \& Farzaneh, M. (2015). Study of Predictability of Gardner's Multiple Intelligence Theory in Selecting Major between Medical and Non-Medical Sciences Students (2014). Journal of Health Policy and Sustainable Health, 1(4). 
Baş, G., \& Beyhab, Ö. (2017). Effects of multiple intelligences supported project-based learning on students' achievement levels and attitudes towards English lesson. International Electronic Journal of Elementary Education, 2(3), 365-386.

Bhalli, M. A., Khan, I. A., \& Sattar, A. (2016). Learning style of medical students and its correlation with preferred teaching methodologies and academic achievement. Journal of Ayub Medical College Abbottabad, 27(4), 837-842.

Codier, E., \& Odell, E. (2014). Measured emotional intelligence ability and grade point average in nursing students. Nurse education today, 34(4), 608-612.

DeCoux, V. M. (2016). Kolb's learning style inventory: A review of its applications in nursing research. Journal of Nursing Education, 29(5), 202-207.

Laxman, K., Sandip, S., \& Sarun, K. (2014). Exploration of preferred learning styles in medical education using VARK modal. Russian Open Medical Journal, 3(3).

Lenox, M. (Producer). (2014, 4/28/2019). Happiness Through Personal Learning. Retrieved from https://slideplayer.com/slide/7302034/

Lunenburg, F. C., \& Lunenburg, M. R. (2014). Applying Multiple Intelligences in the Classroom: A Fresh Look at Teaching Writing. International journal of scholarly academic intellectual diversity, 16(1).

Macnamara, J. (2016). Multiple intelligences and minds as attributes to reconfigure PR-A critical analysis. Public relations review, 42(2), 249-257.

Moghadam, M. B., Moghadam, A. B., Rostaminejad, A., \& Salehian, T. (2015). A Study on the learning Styles of Nursing and Midwifery Students in Yasuj According to the VARK Model (2013). Armaghane Danesh Bimonthly Journal, 20(3), 243-252.

Prithishkumar, I. J., \& Michael, S. (2014). Understanding your student: using the VARK model. Journal of postgraduate medicine, $60(2), 183$.

Rankin, B. (2013). Emotional intelligence: enhancing values-based practice and compassionate care in nursing. Journal of advanced nursing, 69(12), 2717-2725.

Samarakoon, L., Fernando, T., Rodrigo, C., \& Rajapakse, S. (2013). Learning styles and approaches to learning among medical undergraduates and postgraduates. BMC medical education, 13(1), 42.

Singh, Y., Makharia, A., Sharma, A., Agrawal, K., Varma, G., \& Yadav, T. (2017). A study on different forms of intelligence in Indian school-going children. Industrial psychiatry journal, 26(1), 71.

Vizeshfar, F., \& Torabizadeh, C. (2018). The effect of teaching based on dominant learning style on nursing students' academic achievement. Nurse education in practice, 28, 103-108. 